\title{
Violência de gênero: Uma discussão sob a perspectiva de trauma cultural
}

\author{
Martina von Mühlen Poll \\ Fernanda de Oliveira Alves \\ Cláudia Maria Perrone
}

\section{RESUMO}

O estudo possui como objetivo realizar uma discussão acerca da violência de gênero entendida sob a perspectiva de um trauma cultural. Entendemos a violência de gênero como aquela cometida contra as mulheres e contra os sujeitos que escapam à performance de gênero binária e heterossexual. Serão utilizadas como disparadores para discussão considerações teóricas de autoras como Judith Butler e Shoshana Felman. O que escapa ao padrão binário e heteronormativo de gênero é alvo de situações de violência nas quais, devido ao seu caráter repetitivo e de invisibilidade, constituem um trauma cultural uma vez que as manifestações e as vivências que dizem respeito à violência de gênero não conseguem ser devidamente elaboradas e simbolizadas, constituindo sintomas traumáticos sinalizadores do inconsciente cultural.

Palavras-chaves: trauma; violência de gênero; cultura.

\section{ABSTRACT}

\section{Gender violence: A discussion under the perspective of cultural trauma}

The study aims to perform a discussion about the gender violence understood under the perspective of a cultural trauma. We understand the gender violence as the one committed against women and against the subjects who escape from the performance of binary and heterosexual gender. Theoretical considerations by authors as Judith Butler and Shoshana Felman will be used as triggers for discussion. What escapes from the binary and heteronormative standard of gender is target of situations of violence which, due to their repetitive character and of invisibility, constitute a cultural trauma, once that the manifestations and experiences which are related to gender violence cannot be properly elaborated and symbolized, constituting in traumatic symptoms that are markers of the cultural unconscious.

Keywords: trauma; gender violence; culture.

A violência de gênero está presente na sociedade ao longo de sua história, constituindo uma questão complexa e multifacetada que viola os direitos humanos das vítimas. A violência de gênero não é cometida somente contra a sua vítima direta, ferindo toda a sociedade, uma vez que o privado e o público estão em relação e, desse modo, a violência contra um sujeito diz respeito ao social (Felman, 2014). Assim, questionamo-nos sobre as marcas deixadas nos sujeitos que passam por situações de violência e na sociedade como um todo, uma vez que é na cultura que as relações e as subjetividades se constroem.

$\mathrm{Na}$ busca por ampliar o olhar sobre a temática da violência de gênero somos levados às considerações de Felman (2014), a qual fez um estudo sobre a relação entre o campo jurídico, o trauma e a violência. No livro "O inconsciente jurídico", Felman (2014) faz um estudo de caso sobre o julgamento de O. J. Simpson, ocorrido em 1995 em Los Angeles, que descreve um caso de violência doméstica em que o réu foi acusado do assassinato da esposa. A autora

\section{Sobre os Autores}

M.M.P.

orcid.org/0000-0002-4888-7750 Universidade Federal de Santa Maria (UFSM) - Santa Maria, RS tinavmp@gmail.com

F.O.A.

orcid.org/0000-0001-5797-8745

Universidade Federal de Santa

Maria (UFSM) - Santa Maria, RS

falves.psi@gmail.com

C.M.P.

orcid.org/0000-0002-3840-4575

Universidade Federal de Santa

Maria (UFSM) - Santa Maria, RS cmperrone@ig.com.br

\section{Direitos Autorais}

Este é um artigo de acesso aberto e pode ser reproduzido livremente, distribuído, transmitido ou modificado, por qualquer pessoa desde que usado sem fins comerciais. 0 trabalho é disponibilizado sob a licença Creative Commons CCBY-NC.

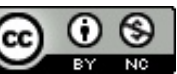




\section{- INTERACÃO EM ET PSICOLOGIA}

analisa o modo como o direito, enquanto um ato linguístico de intervenção cultural, tenta conter o trauma desencadeado pelo crime e traduzi-lo em uma terminologia técnico-jurídica. Nessa análise, Felman (2014) aponta que o julgamento mostrou a indivisibilidade entre trauma privado e coletivo, uma vez que o julgamento remontou aos julgamentos de casos de violência de gênero passados, sinalizando para o inconsciente jurídico, uma instância de repetição de casos traumáticos no campo judicial. 0 que estava presente e produzindo efeitos no julgamento não foi o caso de 0 . J. Simpson apenas, mas todo o trauma coletivo e histórico da violência de gênero. Frente a essa estrutura repetitiva dos processos jurídicos, Felman (2014) aponta que a violência de gênero é um trauma jurídico e, sendo os processos jurídicos e julgamentos dispositivos culturais que dizem sobre uma sociedade, esses expõem uma crise cultural que aponta para o inconsciente da cultura, o qual é, assim como o do campo jurídico, formado de uma memória histórica traumática de violência de gênero composta e refletida pela estrutura repetitiva desses casos. Nesse ponto, então, sinalizamos para a violência de gênero como constituindo um trauma cultural e, em vista disso, problematizamos sobre o que habita esse inconsciente cultural sinalizado pela repetição e pela invisibilidade cultural das manifestações da violência de gênero.

Ao referir-se à violência de gênero como um trauma cultural, Felman (2014) utiliza a abordagem psicanalítica freudiana sobre o trauma. Freud (1920) entende o trauma como advindo da força de uma experiência que não pode ser devidamente reconhecida pelo psiquismo do sujeito devido ao seu caráter de excesso. Por não conseguir ser devidamente reconhecida e simbolizada, a experiência traumática é dotada de um caráter antinarrativo, o que reflete na sua dificuldade de transmissão por meio de uma narrativa. Tal dificuldade de transmissão confere ao traumático um caráter de invisibilidade perante a cultura. Nesse sentido, a cultura mesmo sentindo os efeitos do traumático da violência de gênero possui dificuldade em reconhecê-los e, dessa forma, de elaborá-los e de agregá-los em uma narrativa da cultura, operando na sua negação. Além do caráter antinarrativo do traumático, questionamo-nos sobre as questões culturais que colaboram para a invisibilidade da violência de gênero. Pontuamos que a invisibilidade reflete no não reconhecimento e, assim, na negação do caráter violento dessas situações e vivências.

Além de negar enquanto uma violência, o não reconhecimento do traumático da violência de gênero reafirma o seu caráter de irrepresentabilidade. Acrescentamos, ainda, que ao não conseguir ver e reconhecer a violência essa se torna, assim, um trauma cultural que diz respeito ao inconsciente da cultura, ou seja, ao que não consegue ser visto enquanto tal e, desse modo, produz efeitos culturais cuja repetição mostra o caráter traumático (Felman, 2014). Pontuamos, novamente, que esses efeitos culturais produzem sequelas nas subjetividades, uma vez que consideramos os sujeitos como intrinsecamente sociais, sendo constituídos a partir da linguagem e do que escapa a ela.

Abordamos a temática de gênero através do entendimento de que a sociedade é estruturada por relações de poder hierárquicas entre os gêneros, as quais variam de acordo com a cultura e, assim, são também diversos os efeitos culturais e subjetivos produzidos e reproduzidos por essas relações. Entendemos o gênero como um organizador social da relação entre os sexos que se serve como um meio de decodificar o sentido e compreender as diversas formas de relação e interação humana (Scott, 1995). Pensar o gênero é refletir sobre as relações para além das distinções binárias entre homem/ mulher e masculino/feminino.

Diante disso, reconhecemos a existência de diversas manifestações do gênero em nossa sociedade. Para Butler (2016) o gênero se constrói a partir de significados culturais assumidos pelo corpo sexuado. Assim, as manifestações de gênero são construídas culturalmente pela via discursiva e a identidade de gênero pode ser vista como uma sequência de atos e modos de ser e agir performativos. É através de um discurso generificado sobre o corpo que esse passa a existir.

Ao considerarmos gênero como performance estamos afirmando que ele é construído, mantido e legitimado através de discursos e linguagens normativas da cultura que determinam a identidade de gênero do sujeito. Acreditamos que a performance de gênero é alvo direto da violência de gênero principalmente em relação a pessoas que não se enquadram em uma ordem binária generificada e a pessoas transsexuais. Compreendemos a violência de gênero como sendo a que é cometida contra as mulheres e os sujeitos que escapam à performance de gênero binária e heterossexual. A partir disso, o presente estudo possui como objetivo realizar uma discussão acerca da violência de gênero cometida contra os sujeitos que escapam à performance de gênero binária e heterossexual, violência essa que analisamos sob a perspectiva de um trauma cultural.

\section{O TRAUMA NA CULTURA}

O trauma diz respeito a uma vivência que não conseguiu ser devidamente reconhecida e elaborada (Freud, 1920). 0 não reconhecimento do traumático diz respeito a sua exclusão do campo representacional e simbólico, restando a ele, portanto, manifestações por vias não representacionais, as quais se fazem presentes através da compulsão à repetição, assinalando o caráter atemporal das vivências traumáticas e a necessidade de construção de caminhos possíveis de elaboração. 


\section{- INTERACÃO EM ET PSICOLOGIA}

Devido ao seu lugar psíquico, o trauma não consegue ser transmitido por meio de uma narrativa. 0 excesso traumático não está presente na literalidade de fatos relatáveis, mas sim no que escapa a esses, manifestando-se sob vias não representacionais e sendo marcado por atos e silenciamentos que apontam para uma carga de sofrimento subjetivo que não consegue ser nomeada e dotada de sentido. A narrativa do trauma foi problematizada por Benjamin (1987), o qual relata que os combatentes regressos dos campos de batalha da I Guerra Mundial, ao contrário do que era esperado, voltavam pobres em experiências comunicáveis, silenciosos. Essa observação de Benjamin (1987) sinaliza a dificuldade de transmissão de situações de violência. A dificuldade de transmitir o trauma e de compartilhá-lo por meio da linguagem confere a ele um caráter de silenciamento perante a cultura.

Além do caráter próprio do trauma e sua dificuldade de transmissão refletimos sobre a existência de espaços de simbolização e ressignificação do trauma, uma vez que para que seja construída uma narrativa é necessária uma escuta que a viabilize. Seligmann-Silva (2000) refere que a literalidade das falas de trauma dessensibilizam os espectadores, não havendo espaço para a imaginação e a reflexão. Tais falas viriam marcadas por um excesso de realidade, o qual traria consigo a destruição da capacidade de discernimento entre o real e o irreal visto que a recordação traumática reproduz uma impressão de irrealidade. Juntamente com essa dificuldade de escuta, problematizamos sobre a abertura dos sujeitos a ouvir o traumático, uma vez que essa é uma escuta necessária para a construção de uma narrativa que permita uma elaboração e uma significação do traumático. Nesse ponto, pensamos que os sujeitos subjetivam (ao mesmo tempo em que constroem) a negação cultural em lançar um olhar e uma escuta para o traumático da violência de gênero.

Nesse caminho, podemos pensar que, em relação às situações de violência de gênero, há questões culturais que produzem e reforçam a invisibilidade dessa violência. Pontuamos que ao não reconhecer essas violações a cultura reforça o seu caráter traumático, ao refletir uma estrutura repetitiva dessa violência ao se referir a situações que não foram devidamente elaboradas culturalmente e, portanto, continuam impondo-se sempre em tempo presente (Felman, 2014). Como reflexo, e ao mesmo tempo reprodutor desse cenário, identificamos uma carência de espaços coletivos para a fala, a escuta e a expressão dos sujeitos que sofrem violência de gênero. Questionamentos sobre o que as violências de gênero nos apontam sobre a cultura e o porquê de não haver uma atenção e um olhar para essas questões nos espaços públicos.

Vítimas de violência, ao denunciarem seus agressores judicialmente, passam por um processo desgastante em ter- mos subjetivos. Acreditamos que os espaços que acolhem estes sujeitos não dão conta de reconhecer o trauma vivenciado por eles. São espaços como as Delegacias de Polícia para a Mulher onde prestam queixa e são questionadas com perguntas orientadas por protocolos sobre a violência sofrida e também nos serviços de saúde em que os exames físicos por vezes cometem uma segunda violência, não atentando para a carga de sofrimento subjetivo. Desse modo, os protocolos dos campos jurídico e da saúde podem, ao contrário do que era seu propósito, silenciar as vítimas, possuindo como base uma universalização dos sujeitos e de suas vivências traumáticas que acaba por negar e invisibilizar as singularidades e, assim, dificultar as possibilidades de produção de uma elaboração e narrativa subjetiva da vivência traumática. Além desses espaços no campo judiciário e da saúde, há uma carência de espaços sociais, de encontros coletivos de fala e escuta que poderiam promover um reconhecimento do sofrimento e, assim, da violência ocorrida.

Situamos os espaços culturais de fala e escuta como sendo dotados do potencial de ressignificação e de simbolização do traumático, pois enquanto espaços simbólicos construtores de narrativas também constituem um caminho de elaboração possível, elaboração tanto para os sujeitos quanto para a cultura. Porém, a exclusão desses espaços pode ser vista como uma exclusão do campo simbólico cultural, o que por sua vez reflete em uma dificuldade de elaboração subjetiva do traumático, visto que ele não consegue encontrar um lugar narrativo que permita a elaboração. Nesse sentido, Felman (2014) aponta para a indivisibilidade e a reversibilidade entre o trauma privado e coletivo da violência de gênero, uma vez que um reforça o outro na medida em que reafirmam a sua invisibilidade, fazendo com que a vivência traumática de violência não seja elaborada nem subjetiva e nem coletivamente, permanecendo como uma violência negada por ambos e, desse modo, plena em ressonâncias subjetivas e sociais.

A invisibilidade cultural da violência de gênero e o seu caráter repetitivo de ocorrência podem ser vistos como sintomas provocados por questões que permanecem no inconsciente cultural (Felman, 2014). A partir disso, questionamo-nos o que esses sintomas sinalizam sobre o que habita esse inconsciente da cultura. Pontuamos que ao mesmo tempo em que essa repetição se faz presente ela possui também seu significado negado, uma vez que não se discute com a profundidade necessária o que está no cerne dessa violência, não havendo espaço para uma elaboração coletiva que permita simbolizar o seu caráter traumático causador da repetição. Pensamos que, além de não haver espaço para a significação dos traumas de gênero esses significados permanecem inconscientes, havendo uma naturalização da violência de gênero composta por narrativas universais sobre as situações de violência. Essas narrativas universais são com- 


\section{- INTERACÃO EM ET PSICOLOGIA}

postas por explicações causais perpassadas por questões ideológicas que encobrem o que está no cerne da violência de gênero. Delegar às mulheres, homossexuais, pessoas trans e qualquer sujeito que não se encaixe na ordem binária performativa do gênero um lugar secundário em sua condição de humano parece ser uma ideologia presente por determinados discursos sociais em nossa sociedade. Tais posições ideológicas legitimam a violência ao defenderem que qualquer sujeito que está fora da norma deve ser visto como um inimigo, uma ameaça a essa norma. Além disso, a sociedade carrega reflexos ideológicos de uma memória ainda viva de sua longa história patriarcal. Resulta desse cenário um discurso coletivo superficial que não proporciona possibilidades de construções e elaborações narrativas singulares, lançando na naturalização, na negação e na invisibilidade os sujeitos e as situações de violência e, dessa forma, reafirmando o caráter não simbólico e não representacional dessas violações, que poderia trazer novos elementos de inteligibilidade a estas relações.

Pensamos que as possibilidades e impossibilidades de representação subjetiva e coletiva do traumático na violência de gênero estão diretamente ligadas ao político, uma vez que esse diz respeito aos dispositivos e espaços culturais que reforçam as invisibilidades tanto de sujeitos quanto das vivências desses. Consideramos aqui a própria invisibilidade cultural de mulheres, homossexuais, transsexuais, intersexos e pessoas que vivem seu sexo, gênero e desejo de modo destoante à norma como uma violência. No caminho por ampliar a compreensão sobre as questões que acreditamos perpassar a invisibilidade da violência de gênero, somos remetidos à consideração de que o ato de ver vai além do fisiológico sendo um ato inconscientemente político (Felman, 2014). Nesse sentido, pontuamos que o ato de dotar de visibilidade ou invisibilidade é atravessado pelas questões ideológicas de cada contexto histórico e cultural e essa constatação parte do fato de que inúmeras formas de violação hoje reconhecidas como uma violência já tiveram seu status de violação negado pela sociedade, sendo naturalizadas e consentidas.

Nesse sentido, Felman (2014) aponta para o fato de que culturalmente existe uma espécie de prescrição política para não ver a violência de gênero. Refere que tal prescrição que encobre a visão é motivada pelo ódio, o qual não é reconhecido pela cultura enquanto tal e encontra uma forma de expressão na violência psicológica, moral, física, sexual e nas diversas manifestações que invisibilizam e ditam normatividades e modos de manifestar a subjetividade, de desejar e agir.

0 ódio atrelado às questões ideológicas permanecem de forma inconsciente na cultura, dificultando a construção de discussões por parte da sociedade sobre o que está no cerne da violência de gênero que habita as relações de gênero e a sociedade contemporânea. Entendemos que esse ódio nasce das concepções culturais normativas que atuam contra o que desvia da norma instituída culturalmente por meio da circulação do discurso. Esse ódio que exclui o considerado diferente exclui também da visão a violência que é cometida.

Nessa discussão sobre o que habita o inconsciente cultural no que diz respeito às questões de gênero somos remetidos às considerações de Mountian e Rosa (2015), as quais discutem sobre a posição simbólica e imaginária ocupadas pelos sujeitos no discurso e o que essas posições sinalizam e produzem. As autoras situam a posição no discurso dos sujeitos em situação de violência de gênero como a posição de imigrantes, ou seja, na posição do outro, do que é marcado como estranho e desconhecido ao que é conhecido e familiar. Seguindo nessa ideia, podemos pensar que os estereótipos de gênero e as sexualidades que fogem às normas hegemônicas ocupam esse lugar de outro no discurso.

Sobre disso, problematizamos o que esse aparente estranhamento frente ao outro causa nos sujeitos e os efeitos produzidos. Pensamos que o outro, ao ser visto como estrangeiro à norma, como o que destoa dela, ao mesmo tempo em que está fora da norma também está em relação a ela constituindo-a, ou seja, o fato de estar excluído do discurso serve como delineador do espaço discursivo. As autoras colocam os sujeitos ocupantes da posição de outro no discurso como sujeitos vítimas de situações de violência justamente por estarem situadas discursivamente na posição de estranho, de diferente, sendo vistos como uma ameaça à norma e, portanto, tendo como reflexo as manifestações de violência.

Lembramos que o sujeito, entendido pela psicanálise, é não completo, não podendo ser visto como definido fixamente e o que causa estranhamento a ele é ao mesmo tempo o que aponta para outras possibilidades e desejos. Podemos, então, pensar que a posição ocupada pelo outro diz respeito a esse estranho que causa efeitos no sujeito e, por esse motivo, necessita ser negado. Situamos esse estranhamento causado pelo que é tido como diferente como ligado ao ódio e, portanto, causando efeitos derivados do inconsciente dos sujeitos e da cultura. Tais questões inconscientes que resultam na violência de gênero são encobertas por narrativas centradas na culpabilização das vítimas, o que pode ser visto como uma nova violência ao produzir narrativas prontas e tira do centro da discussão o que essa violência diz sobre as subjetividades produzidas na contemporaneidade.

Ainda em relação o ódio, Lacan (1953-1954) situa-o junto com o amor e a ignorância como uma das paixões fundamentais do ser, sendo composto pela junção das categorias do imaginário e do real. Enquanto o amor aspira ao desenvol- 


\section{W'INTERACÃO EM ET PSICOLOGIA}

vimento do ser do outro, a dimensão imaginária do ódio faz com que esse busque o rebaixamento e a subversão desse outro. Pensando nas questões de gênero e violência, o ódio está associado ao "ser" do outro, ao que é nele projetado e, a partir dessa projeção imaginária agride-se o outro como se a existência desse fosse uma ofensa, uma ameaça. Tais considerações vão ao encontro da discussão de Mountian e Rosa (2015) sobre a ameaça que é projetada nos sujeitos cuja performance de gênero escapa à norma, como se esses representassem um perigo para si.

Esse ódio que desemboca nas situações de violência é tido por Lacan (1953-1954) como sendo revestido no discurso civilizatório de muitos pretextos e racionalizações. Ao estarem revestidas de pretextos, as ações violentas decorrentes do ódio são de certo modo consentidas culturalmente. Nesse sentido, destacamos o ódio como um empuxo a nomear, a traduzir o mal-estar, assumindo a partir disso diversas formas possíveis. Dentre elas há formas patológicas que fazem do ódio o ponto de união em torno do que é tido como pior: juntome com o outro para odiar o terceiro. Essa operação provoca a nomeação de quem somos nós e de quem são eles, as diferenças internas diminuem e a projeção do mal torna-se um fator de fortalecimento identitário e de desumanização do outro, desse modo, esse outro que é tido como diferente é objetificado a partir da sua diferença. Essa objetificação do outro tem como reflexo as ações violentas, uma vez que o outro não é visto como um sujeito e sim como um objeto que causa mal e, como objeto, é submetido a violências que buscam o seu rebaixamento. Ainda sobre esse ponto, destacamos que o ódio possui uma função erótica nem sempre reconhecida. Ele incita ao excesso e a disjunção entre ternura e erotismo, que passa a operar como fator de excitação.

\section{GÊNERO E PERFORMANCE NA CULTURA}

O discurso e a ação violenta por parte de quem não aceita aquele que foge à norma social vigente e pelo que é considerado diferente do padrão hegemônico podem ser percebidos nos altos índices de violência contra travestis e transsexuais, como também em suas próprias invisibilizações nos espaços da cidade, nos centros educacionais e em lugares de trabaIho. Invisibilização nos espaços públicos é uma forma de violência, uma vez que priva esses sujeitos dos locais de construção simbólica, não havendo espaços onde esses possam manifestar suas singularidades e, desse modo, construir narrativas, sendo marcados justamente pela exclusão do espaço discursivo. Dessa forma, por vivermos em uma sociedade que determina formas de ser e de se manifestar enquanto homem e mulher, os sujeitos que fogem a tais determinações e padronizações de gênero acabam por ter reconhecimento parcial de suas reivindicações políticas, com prejuízo de seu reconhecimento enquanto sujeitos, demarcando aí a violência sobre a performance de gênero que escapa ao binário e heterossexual.

0 gênero deve ser posto como um meio de falar de sistemas de relações sociais entre os sexos. Para isso, é preciso pensar como o gênero se constrói, legitima-se e se transforma entre os sujeitos, suas relações sociais e a natureza e suas interrelações (Scott, 1995). Para Judith Butler (2016) gênero é um ato performativo que se dá de maneira contínua, através da estilização do corpo, da maneira do sujeito ser e de fazer performances. Assim, entende-se o corpo como uma construção, sendo dotado de significados culturais e o gênero como um efeito das performances. Nesse sentido, Butler (2016) fala que não há uma identidade de gênero que produza as expressões do gênero, mas, ao contrário, que a identidade é performativamente constituída por tais expressões. Desse modo, podemos entender que o gênero não é uma forma de "ser" no mundo, mas sim, uma forma de "estar", visto que, ao ser uma construção discursiva, possui um caráter dinâmico e não fixo e imutável.

Pensar o gênero passa a ser, então, a forma de pensar as relações hierárquicas e de poder existentes entre diferentes formas de apresentação de gênero. Apontamos que há uma invisibilidade cultural das formas de apresentação de gênero que escapam da ordem performativa de gênero binária e heterossexual, invisibilidade essa que se estende a esses sujeitos e, devido ao caráter repetitivo da violência que sofrem, faz com que essa se configure como um trauma cultural.

Ao dizermos que homens e mulheres agem de formas específicas pelo simples fato de serem homens e mulheres, colaboramos para manter uma ordem social binária, generificada e heterossexual. 0 fato de vivermos em uma estrutura patriarcal que privilegia o homem como sujeito universal faz com que sejam construídos padrões de comportamento esperados para cada sexo. Para Scott (1995) é preciso rejeitar o caráter fixo e permanente da oposição binária através de uma historização e desconstrução autêntica do que nos é entendido como diferença sexual.

A forma de apresentação de gênero irá depender de como cada corpo irá se expressar e se comunicar com o mundo e seu entorno. Pensar a possibilidade de distintas apresentações de gênero é entender que existem sujeitos para além das noções binárias e pré-concebidas do homem/mulher e masculino/feminino. Butler (2016) afirma que somos levados a pensar de forma binária devido à estrutura social na qual estamos inseridos. A autora usa termos como matriz/ordem heterossexual e heterossexualidade compulsória para designar a forma de pensar da nossa sociedade. Notamos, então, o quanto o trauma de gênero está incrustado na linguagem, uma vez que a noção binária e heterossexual é tida como da- 
da e naturalizada na estrutura social, sendo que o que escapa a ela é o que escapa ao discurso.

A ordem heterossexual que serve como noção de explicação de mundo para muitos sujeitos se mantém e se reproduz em espaços representativos, jurídicos e acadêmicos. Olhando mais atentamente, observamos que a ordem heterossexual se estende até mesmo entre sujeitos homossexuais, os quais, nesses espaços públicos, são levados a se enquadrarem de alguma forma na ordem binária e heteroxessual, ou seja, a encaixarem-se em narrativas já existentes, que reproduzem o padrão binário e heterossexual, invisibilizando e negando outras e múltiplas narrativas possíveis. Isso ocorre pela ideia de enquadrar o sexo, gênero e desejo em uma norma de dependência na qual o sexo determinará o gênero e esse determinará o desejo. E, sendo uma norma, exclui ou dota de invisibilidade o que escapa a essa norma, invisibilidade que subtrai a linguagem e o espaço público marcando, assim, uma violência que se configura como um trauma subjetivo e cultural. Essa invisibilidade diz também de uma dificuldade de assimilação subjetiva e cultural do que escapa à norma, configurando um trauma e permanecendo sob a forma de um excesso na cultura, de algo que escapa. A intenção de Butler (2016) é demonstrar que as formas de expressões de gênero não vêm necessariamente de um sexo específico, abrindo a possibilidade para outras formas de gênero.

Butler (2016) afirma que os sujeitos apenas se tornam inteligíveis ao adquirir seu gênero em conformidade com os padrões reconhecíveis de inteligibilidade de gênero, o que reflete na invisibilidade e não reconhecimento do que escapa a esses padrões. A autora situa os gêneros inteligíveis como aqueles que mantêm uma relação de coerência entre sexo, gênero, prática sexual e desejo. Dessa forma, homossexuais e transexuais, por exemplo, são colocados pela cultura em uma posição diferente ao padrão heteronormativo hegemônico no qual há uma não aceitação dessas identidades, sendo elas vistas apenas como o que escapa ao padrão hegemônico, ou seja, a partir de um não reconhecimento dessas identidades enquanto tal, uma vez que o centro para o reconhecimento está situado no padrão binário e heterossexual. Aqui, lembramos novamente as observações de Mountian e Rosa (2015) de determinados sujeitos serem situados em relação ao discurso como o que escapa desse e que, ao mesmo tempo que o molda, é tido como ameaça, como estrangeiro.

\section{VIOLÊNCIA DE GÊNERO COMO TRAUMA CULTURAL}

Com a compreensão de que a psicanálise se desenvolve refletindo sobre o sexual que está sempre presente na vida do sujeito, questionamos como esta ainda se mantém afasta- da de questões que extrapolam o binarismo de gênero, ou seja, com questões para além das noções já concebidas de homem e mulher como o são as identidades trans, por exemplo (Porchat, 2013). Aran (2006) traz que a transexualidade por ser a não conformidade entre sexo e gênero ainda é tratada como patologia pelos discursos da saúde e também pela psicanálise. Entendemos que esses discursos constroem saberes e padrões normativos que dizem respeito a uma moralidade do que é aceitável e do que não o é. A patologização da condição transsexual contribui para uma invisibilização destes sujeitos enquanto seres de desejo, pois enquadrá-los em uma patologia é um ato de violência que impede seu reconhecimento humano. Com isso, podemos pensar que a não aceitação destas identidades se reflete como violência e, por consequência, como um trauma de gênero na cultura, ocorrendo compulsão à repetição dessa violência.

0 pensamento essencialista de que o corpo deve apresentar características condizentes com o sexo biológico gera discursos biologizantes e patologizantes da condição generificada do sujeito. A noção de que uma mulher deve ter um corpo e uma ação feminina ou que homens devem ter corpos e ações masculinas é o que dá argumentos a uma violência sobre a performance de gênero. Entende-se que independente do sexo biológico, cada sujeito é livre para construir sua identidade através das identificações, desejos e fantasias que lhe cabem.

Haraway (2009) em seu texto "Manifesto ciborgue: Ciência, tecnologia e feminismo-socialista" no final do século XX, afırmava que a ciência e a tecnologia já estão impregnadas em todo e qualquer sujeito sendo parte indissociável do corpo e da experiência de cada um no mundo. Explicações deterministas que não cabem, visto que entendemos que os discursos e as transformações corporais que a ciência e a tecnologia produzem sobre os corpos são perpassados pela cultura e, dessa forma, carregam as marcas de uma cultura marcada pela violência de gênero, promovendo a invisibilidade do que escapa à norma e, dessa forma, podemos entender que os discursos científicos e tecnológicos reforçam o trauma de gênero.

Assim, o discurso dos sujeitos e da cultura sobre os traumas de gênero permanece, até a atualidade, como um discurso esvaziado no qual a capacidade de representação não se efetiva. Nesse cenário, a repetição dos casos de violência de gênero ocorre diariamente. A violência de gênero é uma violência que recai diretamente sobre os sujeitos e seus corpos, visto que restringe as formas de manifestação corpórea e as formas de subjetivação. Por não haver o reconhecimento por parte da cultura de algumas formas de manifestações corporais, por estas não se enquadrarem no padrão heteronormativo que irá determinar que homens devem ser masculinos e mulheres femininas, pessoas que constroem no corpo, ges- 


\section{- INTERACÃO EM ET PSICOLOGIA}

tos e atos manifestações de gênero que não condizem com o sexo biológico são constantemente violentadas por um discurso de recriminação a qualquer performance de gênero que esteja fora da norma binaria e heterossexual.

Butler (2016, p.241) afirma que "Os gêneros distintos são parte do que 'humaniza' os indivíduos na cultura contemporânea; de fato, habitualmente punimos os que não desempenham corretamente seu gênero". Para ela, são os atos de gênero que criam a própria ideia de gênero e que sem tais atos não haveria gênero algum por não haver nenhuma essência que ele expresse e exteriorize. Isso demarca o quanto o gênero é construído culturalmente através dos discursos que circulam significados em cada sociedade, falsificando, assim, concepções essencialistas sobre gênero. Ressaltamos que esses mesmos discursos que constroem estereótipos de gênero são os que dotam de invisibilidade o que escapa a eles, sendo perpassados por questões ideológicas. Nesse sentido, não há um status ontológico e constitutivo da realidade, uma vez que o corpo, enquanto gênero, é marcado pelo performativo.

Butler (2016) estabelece que atos, gestos e desejos produzem o efeito de núcleo ou substância interna do sujeito, porém o produzem na superfície do corpo. Desse modo, os atos performativos de gênero fabricam uma realidade como se essa derivasse de uma essência interna, quando o que ocorre é que essa interioridade é efeito e função de um discurso social e político, "da regulação pública da fantasia pela política de superfície do corpo, do controle da fronteira do gênero que diferencia interno de externo e, assim, institui a 'integridade' do sujeito" (Butler, 2016, p.235).

Diante disso, entende-se que o sujeito é acima de tudo construído no discurso o qual, sendo uma construção social e política institui uma ordem social generificada e binária, é reproduzida por atos performativos e repetitivos de gênero. Para Butler (2016) isso vai além da capacidade individual do sujeito, pois manter a estrutura binária do gênero através da performance deve ser compreendido como algo fundador e consolidador do sujeito na contemporaneidade. Assim, repetem-se performances de gênero para legitimá-las. Entendemos que essa legitimação ocorre também às custas de dotar de invisibilidade e exclusão ao que escapa à estrutura binária de gênero, o que colabora e, ao mesmo tempo, é um reflexo das concepções essencialistas sobre gênero.

Nesse cenário, em que a legitimação das performances de gênero binárias ocorre por suas repetições, podemos entender que o que escapa a essa norma é sentido como uma ameaça à sua manutenção cultural, refletindo nas manifestações de violência que excluem da visibilidade o que não se legitima na norma binária e heterossexual. Além disso, as subjetividades e as relações se constroem em uma cultura que carrega consigo uma herança traumática causada por um padrão histórico e coletivo que repete compulsivamente a violência de gênero. Sendo que a violência de gênero possui uma naturalização acompanhada pelas concepções essencialistas de gênero, as quais estabelecem o gênero por um padrão a-histórico e fixo.

\section{CONCLUSÃO}

Diante do que foi aqui exposto, ressaltamos o caráter de trauma cultural que a violência de gênero configura dado o seu padrão repetitivo e coletivo, bem como a invisibilidade a que são lançados os sujeitos e suas vivências. Invisibilidade essa que está relacionada à instituição da norma binária de gênero e heterossexual que exclui o que escapa a ela.

Nesse cenário, percebemos que a violência de gênero é dirigida aos sujeitos cujas performances de gênero escapam à norma binária e heterossexual, sendo uma violência dirigida às subjetividades e aos corpos desses sujeitos, a qual busca restringir a estilização desses corpos, a maneira do sujeito fazer performances. Considerando que as performances de gênero possuem como palco principal os espaços públicos, compreendemos que isso reflete diretamente na negação ou na restrição desse espaço a esses sujeitos.

Por considerarmos que a experiência do sujeito na cultura perpassa pela forma que este concebe e apresenta seu gênero, entendemos que atos de violência colaboram com discursos de desqualificação dos indivíduos enquanto sujeitos. Quando a capacidade de ser sujeito é ameaçada pela cultura têm-se o pensamento da não existência destas pessoas e de seu sofrimento.

Esse cenário assinala a necessidade de discussões profundas sobre as questões que perpassam a violência de gênero e que permanecem não reconhecidas e negadas. É preciso problematizar o que a estrutura repetitiva e traumática sinaliza sobre o inconsciente cultural no que diz respeito às questões de gênero. Acreditamos que esse debate e construção é possível através da criação de espaços e dispositivos culturais que, através da fala e da escuta, englobem discursivamente as diversas possibilidades subjetivas, desejantes e performativas, para que estas possam ter visibilidade e outras posições possíveis no discurso que não a de estrangeiro, de diferente que ameaça. Nesse sentido, situamos a criação desses espaços e dispositivos como elementos da simbolização e da ressignificação do traumático, com a possibilidade de construção de narrativas singulares que permitam uma elaboração subjetiva e cultural sobre as vivências de violência de gênero, passando pelo reconhecimento dessas questões e, assim, havendo a possibilidade de uma mudança cultural. 


\section{W'INTERACÃO EM EF PSICOLOGIA}

\section{CONTRIBUIÇÃO DE CADA AUTOR}

M.M.P., F.A.O. e C.M.P. foram responsáveis pela conceitualização, metodologia e redação final (revisão e edição). M.M.P. e F.A.O executaram a investigação e a redação inicial do artigo (rascunho) e C.M.P. realizou a supervisão do artigo.

\section{DECLARAÇÃO DE CONFLITOS DE INTERESSES}

Os autores declaram que não há conflitos de interesses no presente artigo.

\section{DECLARAÇÃO DE FINANCIAMENTO}

O estudo foi financiado pela bolsa de mestrado da primeira autora concedida pela Capes (Coordenação de Aperfeiçoamento de Pessoal de Nível Superior).

\section{REFERÊNCIAS}

Arán, M. (2006). A transexualidade e a gramática normativa do sistema sexo-gênero. Ágora, 9, 49-63.

Benjamin, W. (1987). O narrador: Considerações sobre a obra de Nikolai Leskov. Em W. Benjamin (R. P. Sergio, Trad.), Magia e técnica, arte e política: Ensaios sobre literatura e história da cultura (3ª ed., pp. 197-221). São Paulo: Brasiliense.

Butler, J. (2016). Problemas de gênero: Feminismo e subversão da identidade (A. Renato, Trad.). Rio de Janeiro: Civilização Brasileira.

Felman, S. (2014). O inconsciente jurídico: Julgamentos e traumas do século XX (A. B. Sudatti, Trad.). São Paulo: Edripro.
Freud, S. (1920). Além do princípio de prazer. Em S. Freud (S. Jayame, Trad.), Além do princípio de prazer, Psicologia de Grupos e outros trabalhos (pp. 13-79). Rio de Janeiro: Imago.

Haraway, D. J. (2009). Manifesto ciborgue: Ciência, tecnologia e feminismo-socialista no final do século XX. Em Haraway, D. J. \& Kunzru, H. (T. Tadeu, Org. e Trad.). Antropologia do ciborgue: As vertigens do pós-humano ( $2^{\mathrm{a}}$ ed., pp. 33-118). Belo Horizonte: Autêntica Editora.

Lacan, J. (1953-1953). O conceito da análise. Em J. Lacan (M. Betty, Trad.), Os escritos técnicos de Freud (pp. 311327). Rio de Janeiro: Jorge Zahar Editor.

Mountian, I., \& Rosa, M. D. (2015). O outro: Análise crítica de discursos sobre imigração e gênero. Psicologia USP, 26(2), 152-160. http://dx.doi.org/10.1590/01036564D20150001

Porchat, P. (2013). Tópicos e desafios para uma psicanálise queer. Em F. S. T. Filho et al. (Org.), Queering: Problematizações e insurgências na psicologia contemporânea (pp. 99-112). Cuiabá: EdUFMT.

Scott, J. W. (1995). Gênero: Uma categoria útil de análise histórica. Educação \& Realidade, 20(2), 71-99.

Seligmann-Sivla, M. S. (2000). A história como trauma. Em A. Nestrovski, \& M. S. Seligmann-Sivla (Org.), Catástrofe e representação (pp. 73-99). São Paulo: Escuta.

Recebido em: $31 / 12 / 2016$ Primeira decisão editorial em: 23/10/2017 Aceito em: 20/12/2017 